\title{
Down's syndrome in twins of unlike sex
}

\author{
A AVNi, J AMIR, E WILUNSKY, M B M KATZNELSON, AND \\ S H REISNER
}

From the Department of Neonatology, Beilinson Medical Center, Petah Tiqva; Tel Aviv University Sackler School of Medicine; and the Institute of Genetics, Sheba Medical Center, Tel Hashomer Hospital, Israel.

SUMmARY The occurrence of Down's syndrome in both dizygotic twins appears to be very rare. A case of twins of unlike sex is reported, in which chromosomal analysis showed trisomy 21 in both of them, while the parental karyotypes were normal. This is the third reported case of such a constellation, and the second one in which infant and parental chromosomal analysis was done.

Concordance for Down's syndrome in dizygotic twins is rare. ${ }^{1}$ Only a few cases have been reported, and in many of them the diagnosis of dizygosity has been based on clinical findings or on the examination of the placenta and membranes alone. The problem of proving zygosity does not arise, of course, in the case of twins of opposite sex. Until now, two such cases have been reported ${ }^{2} 3$ and only in one was the diagnosis of Down's syndrome proved by chromosomal analysis. ${ }^{3}$

We wish to report twin infants, a boy and a girl. with Down's syndrome because of trisomy 21 .

\section{Case reports}

Twins, a male and a female, were born to a 41-yearold healthy mother, G16, P15, A2, of Yemenite (Haban) origin. The father was 47 years old and healthy. Eleven other children (five boys and six girls) were healthy and normal. One female infant was born preterm and died 6 days after delivery. The parents were distantly related.

The date of the last menstrual period was unknown. During the early part of the pregnancy the mother had some episodes of vaginal bleeding and again in the sixth month. Membranes ruptured 24 hours before a spontaneous delivery. The first twin, a girl, was born by vertex presentation; Apgar score at 1 minute was 9 , birth weight $1200 \mathrm{~g}$, head circumference $26 \mathrm{~cm}$.

The second twin, a boy, was born by breech presentation, with a birth weight of $1480 \mathrm{~g}$; Apgar score at 1 minute was 6 , and 9 after 5 minutes. Shortly after birth he began grunting, had chest

Received for publication 16 July 1982. retractions and cyanosis, and needed supplemental oxygen of 40 to $60 \%$. At 3 hours of age, they were transferred to the Neonatal Intensive Care Unit at the Beilinson Medical Center.

The female twin was admitted in good condition with no signs of respiratory distress. Estimation of gestational age by the Dubowitz score ${ }^{4}$ and by examination of the eye lens ${ }^{5}$ was 32 weeks. Clinical features of Down's syndrome were obvious (fig 1). Her clinical course was uneventful during the first days, but on the sixth day apnoeic spells occurred, which were successfully treated with theophyllin. On the tenth day, a grade $2 / 6$ systolic murmur was heard for the first time at the left lower sternal border. The chest $x$-ray and ECG were compatible with the diagnosis of a ventricular and atrial septal

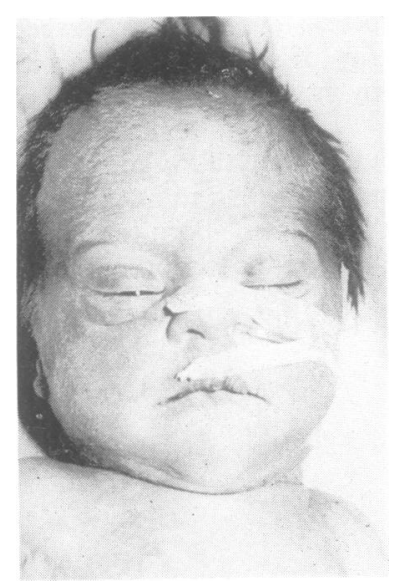

FIG 1 Female twin. 
defect with a left to right shunt. Her clinical condition was good and there were no signs of heart failure. She was discharged in good condition at 60 days of age, weighing $2560 \mathrm{~g}$.

The male twin also had typical signs of Down's syndrome (fig 2). On admission he had severe respiratory distress and chest $x$-ray showed severe hyaline membrane disease. In spite of treatment with assisted ventilation, his condition deteriorated rapidly and, at the age of 30 hours, he died. Parental consent for necropsy was refused.

\section{CHROMOSOMAL ANALYSIS}

Karyotypes were made on peripheral lymphocytes by a modification of the banding technique of Seabright. ${ }^{6}$ Fifty-two cells of the female twin and 43 of the male twin were counted, the girl showing $47, X X,+21$ and the boy $47, X Y,+21$. The father and mother had normal karyotypes.

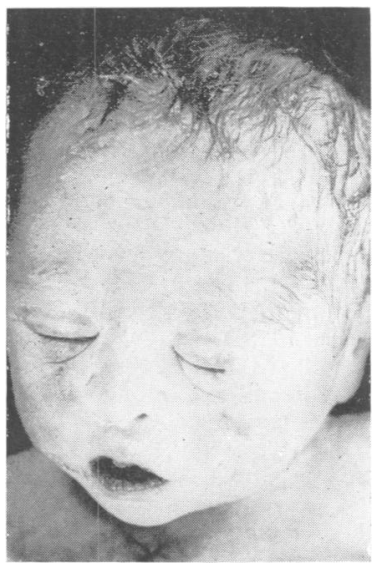

FIG 2 Male twin.

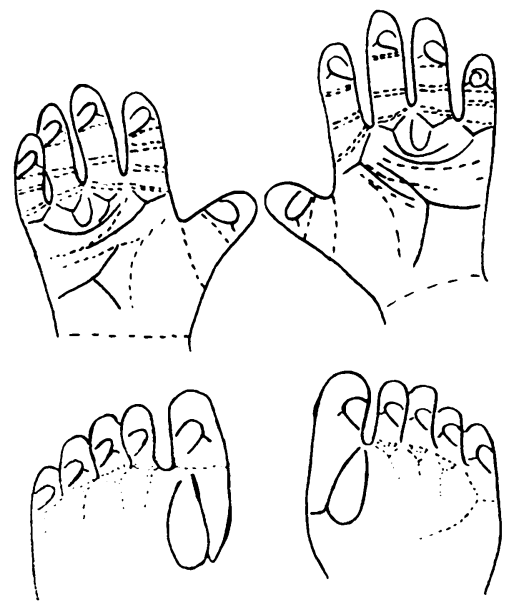

FIG 3 Dermatoglyphs of the female twin.

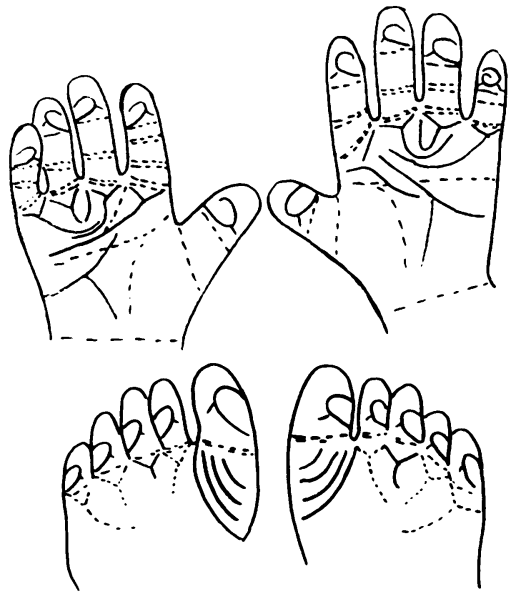

FIG 4 Dermatoglyphs of the male twin.

\section{DERMATOGLYPHIC ANALYSIS}

(FIGS 3 AND 4)

Palm and foot prints were taken from the two infants. Each one had nine ulnar loops on their digits and one single whorl on their right fifth finger. In both cases a bilateral distal loop in the 3rd interdigital area was observed. The sum of the maximal atd angle of the boy was $194^{\circ}$ and that of the girl $177^{\circ}$. The main line index in both cases was very high, 11.11. A single simian line was observed $\mathrm{cn}$ the boy's left palm.

The patterns of the toes of the boy were all fibular loops, whereas on the girl's toes there were eight fibular loops and two arches on both fifth toes. There were tibial arches on the hallucal areas of the boy. The girl had small distal loops (a small loop being defined as a loop having a ridge count of 1 to 20) on her hallucal areas.

In addition, both infants had the typical deep furrow between the first and second toes.

\section{Discussion}

The occurrence of Down's syndrome in twins has been extensively studied, ${ }^{1-3}$ 7-14 the conclusion being that in monozygotic twins concordance is the rule, while in dizygotic twins the majority of cases are discordant. Only two cases of triplets, the first with one infant affected ${ }^{15}$ and the second with two of the three affected ${ }^{16}$ have been reported. In these cases there was heterozygosity between the normal and affected children.

Chromosomal studies in two cases of dizygotic twins in which only one of them was affected showed the interesting finding of a transient chimaerism in the lymphocytes of the normal infants, the hypothesis 
being the passage of lymphocytes from one fetus to the other in an early stage of fetal life. ${ }^{17} 18$

A number of reports of dizygotic twins concordant for Down's syndrome have been published since 1933. ${ }^{7}$ Most have been pairs of the same $\operatorname{sex}^{17819}$ and the diagnosis of dizygosity, which was based on clinical grounds alone, was doubtful in most cases.

Only two cases concordant for Down's syndrome have been reported in dizygotic twins of unlike sex. ${ }^{2} 3$ In the case of Nicholson and Keay ${ }^{2}$ the diagnosis was based on characteristic clinical findings, but no chromosomal analyses were done. In 1972, Fielding and Walker ${ }^{3}$ reported Down's syndrome in twins of opposite sex with both twins having trisomy 21 . They concluded that the chance of dizygous twins being born with the syndrome should be expected to be less than 1:300000. In 1964, McDonald ${ }^{20}$ reported another two sets of twins of unlike sex concordant for Down's syndrome, without any clinical or laboratory information. It is possible that some of the like sex pairs concordant for this syndrome which have been reported were, in fact, dizygotic. Greulich, ${ }^{19}$ in 1975 , reported such a pair of female twins with Down's syndrome, who were re-examined at the age of 43 years and proved to be dizygotic by clinical and radiographic signs as well as by blood group analysis.

The simplest explanation for such a rare event is, of course, the possibility of an older mother giving birth by chance to dizygotic twins both affected by Down's syndrome resulting from her increased age. The possibility of non-disjunction at the first meiotic division in the female, followed by fertilisation of the egg nucleus by one sperm, and concomitantly of the second polar body by a different sex chromosome carrying sperm, as was speculated by Fielding and Walker, ${ }^{3}$ seems to be more remote.

We wish to thank Dr F Doolitzky, Dr Ezra Elian, and Professor Goldman for referring the infants to our Unit.

\section{References}

1 Zellweger H. Familial aggregates of the 21 trisomy syndrome. Ann NY Acad Sci 1968;155:784-92.
2 Nicholson DN, Keay AJ. Mongolism in both twins of opposite sex. Arch Dis Child 1959;32:325-7.

3 Fielding DW, Walker S. Dizygotic twins with Down's syndrome. Arch Dis Child 1972;47:971-3.

4 Dubowitz MS, Dubowitz V, Goldberg C. Clinical assessment of gestational age in the newborn infant. $J$ Pediatr 1970;77:1-10.

5 Hittner HM, Hirsch NJ, Rudolph AJ. Assessment of gestational age by examination of the anterior vascular capsule of the lens. J Pediatr 1977;91:455-8.

- Seabright M. A rapid banding technique for human chromosomes. Lancet 1971 ;ii:971-2.

7 Keay AJ. The significance of twins in mongolism in the light of new evidence. J Ment Defic Res 1958;2:1-7.

8 Jervis GA. Mongolism in twins. Am J Ment Defic $1943 ; 47: 364-9$.

๑ Rassore-Quartino A. Gemelli monozigotici con mongolismo concordante. Acta Genet Med Gemellol (Roma) 1967;15:395-401.

10 Shapiro LR, Farnsworth PG. Down's syndrome in twins. iv Clin Genet 1972;3:364-70.

11 De Wolff E, Scharer K, Lejeune J. Contribution a l'étude des jumeaux mongoliens. Un cas de monozygotisme heterocaryote. Helv Paediatr Acta 1962;17:301-28.

12 Tefler MA, Baker, D Bergman M. Twins, probably $D$ monozygotic, displaying Down's syndrome, physical and functional mirror-imaging, and discordant for congenital heart disease. Am J Ment Defic 1972;76:391-6.

13 Shiono H, Kasahara S, Toyoguchi A, et al. Genetics studies on twins of Down's syndrome with 47 chromosomes. Tohoku J Exp Med 1971 ;105:309-16.

14 Friedmann A. Mongolism in twins. Am J Dis Child $1955 ; 90: 43-50$.

15 Shiono H. Down's syndrome with trisomy in one triplet. Am J Dis Child 1977;131:522-4.

16 Liberfarb RM, Atkins, L Holmes LB. Down syndrome in $\mathbb{D}$ two of three triplets. Clin Genet 1978;14:261-4.

17 Massimo L, Gemme G, Vianello MG, et al. Studio di una copia di gemelle dizigotici di cui uno mongoloide di 3 cellule con trisomia 21. Acta Genet Med Gemellol (Roma) 1966;15:208-11.

18 Rohmer A, Ruch JV, Schneegans E, et al. Jumeaux dizygotes, l'un $47 \times X 21+$ et cliniquement mongolien, 3 l'autre $46 \times X / 47 \times X 21+$ et cliniquement non mon- 0 golien. Arch Fr Pediatr 1970;27:667-8.

19 Greulich W. A case of mongolism in DZ female twins studied at 10 and then at 43 years of age. Acta Genet Med $\dot{ }$ Gemellol (Roma) 1975;24:47-61.

20 McDonald AD. Mongolism in twins. $J$ Med Genet $1964 ; 1: 39-41$.

Requests for reprints to Dr A Avni, Department of Neonatology, Beilinson Medical Center, Petah Tiqva N 49100 , Israel. 